\title{
Social Contexts of Living with HIV/AIDS in the Eastern Region of Ghana
}

\author{
Adobea Yaa Owusu'
}

\begin{abstract}
The livelihoods of persons living with HIV/AIDS (PLWHAs) in Ghana and sub-Saharan Africa have generally been under-researched using the social context approach. Employing the social context explanatory framework, we explore the livelihoods and challenges facing 38 PLWHAs in the Lower Manya Krobo Municipality (LMKM) in the Eastern Region of Ghana. LMKM has the highest prevalence of HIV/AIDS in Ghana. In-depth interviews have been conducted with participants who are out-patients at either of the two HIV/AIDS clinics in the study area. Their family relations, healthcare, healthcare seeking, and health status have been explored. The findings show the participants to generally be poor, have poorer health, and to have had some challenges to healthcare seeking, including food insecurity. They also lack sufficient support from family and romantic partners. Most have family members and romantic partners who had succumbed to HIV/AIDS. The participants generally have a high burden of child dependents, including orphans from HIV/AIDS. Our explanatory model confirms that the participants are caught at the interphase of intrapersonal, interpersonal, community, and national vulnerabilities that are interdependent and reciprocal. Safety-net provisions such as the National Health Insurance scheme provide them with inadequate social protection. For improved health status and general livelihood, we recommend more pro-active social support for the participants and their dependents. Furthermore having stakeholders make greater efforts is recommended for strengthening Ghana's economy against shocks.
\end{abstract}

\section{Keywords}

HIV/AIDS • Qualitative research • Vulnerability • Livelihood • Comorbidities • Social context framework • Lower Manya Krobo Municipality • Ghana

\footnotetext{
1 Correspondence to: Adobea Yaa Owusu (Assoc. Prof.), Institute of Statistical, Social and Economic Research P. O. Box LG 74, University of Ghana, Legon, Ghana. E-mail: ayowusu@ug.edu.gh ORCID: 0000-0003-2223-7896
}

To cite this article: Owusu, A. Y. (2019). Social contexts of living with HIV/AIDS in the eastern region of Ghana. Istanbul Üniversitesi Sosyoloji Dergisi, 39(2), 425-454. https://doi.org/10.26650/SJ.2019.39.2.0109 
Previous researchers have documented the absence of contextual issues that persons living with HIV/AIDS (PLWHAs) face, especially pertaining to poor African settings with negligible social protection from the state (Tenkorang et al., 2017; Teye-Kau, Tenkorang, \& Agyei, 2018). Being a vulnerable group, the daily livelihoods and general well-being of PLWHAs are critically important, particularly given the high impact the epidemic has on their communities. Previous researchers have observed that the contexts of the livelihoods of vulnerable persons, such as those who live in abject poverty, put them at risk of acquiring HIV. Similarly, living in such depraved conditions can affect how the infection is managed (Fobil \& Soyiri, 2006; Langmagne, 2016; Lund \& AgyeiMensah, 2008). Additionally, giving prominence to some of PLWHAs' known and extremely challenging living situations means drawing the attention needed to be able to bring them some relief. Being a vulnerable group, their living situations are usually covert (National Association of Persons Living with HIV/AIDS [NAP+] et al., 2014). This is further worsened by the known stigma and discrimination that comes with being HIV-positive in sub-Saharan Africa in general and Ghana in particular (Mill, 2003).

Ghana has had its fair share of the scourge from the HIV/AIDS pandemic. Ghana's first case of HIV/AIDS was confirmed in 1986. The national 2016 prevalence rate for 15-24 year olds was $2.4 \%$, and the incidence rate was $1.1 \%$ (National AIDS Control Programme [NACP], 2016). UNAIDS (2017) recorded a total of 15,000 AIDS-related deaths in Ghana in 2016, of which 2,500 were children between 0-14 years old. 270,000 children have become orphans (ages 0-17 months) due to AIDS. Ghana, with over 1\% of its inhabitants infected with HIV, has a generalized epidemic (Ghana AIDS Commission [GAC], 2019), although the HIV rates in Ghana are lower than those of the surrounding countries (UNAIDS, 2017). These statistics set the tone for reckoning some of the livelihood and socio-economic challenges HIV/AIDS has imposed on individuals, families, communities, and the national.

Agormanya, one of the 40 national HIV sentinel sites in the Eastern Region, has had the highest rates of infection since the pandemic emerged in Ghana, except for 2011 and 2014 (UNAIDS/GAC, 2014; GAC, 2015a). In fact, the first confirmed HIV/AIDS case in the country was from Agormanya (Teye-Kau et al., 2018). Although the rates in Agormanya have decreased over time (i.e., 13\% prevalence in 1999 [NACP, 2003] and $11.6 \%$ in 2013 [GAC, 2015b]), Agormanya's current HIV/AIDS prevalence rate of 5.6\% (GAC, 2019) is disproportionally high compared to the rest of the country $(1.69 \%$ in 2018; GAC, 2019). Thus, the Eastern Region has sustained most regularly the overall highest HIV/AIDS rates among the regions in Ghana since data collection began.

The burden of the HIV/AIDS menace on inhabitants in the Lower Manya Krobo Municipality (LMKM), the catchment area of Agormanya, is of greater interest. Previous researchers (e.g., Fobil \& Soyiri, 2006; Lund \& Agyei-Mensah, 2008; 
Langmagne, 2016; Teye-Kau et al., 2018) have highlighted the contextual issues and pointed out the reciprocal effects these and HIV/AIDS have on Agormanya's inhabitants and surrounding vicinities. Different forms of material and non-material poverty have been stressed as accounting for the high prevalence of HIV/AIDS in Agormanya and nearby localities. These include financial poverty, comparatively high unemployment/ underemployment rates, deficient housing, and overcrowding. Others are near-alienated levels of several social problems such as single parenting, school dropout and truancy, teenage pregnancy, and childbirth out of wedlock (Langmagne, 2016; Tenkorang, Owusu, \& Laar, 2017a). For example, a couple of years ago, LMKM had the worst youth unemployment rates in the Eastern Region (Ghana Statistical Service [GSS], 2013, 2014; Owusu \& Laar, 2018). Furthermore, other forms of social problems have accompanied the trail of HIV/AIDS in the locality. These include the untimely termination of marriages as spouses die and the surviving ones loses potential sources of social support, high numbers of orphaned and vulnerable children (OVCs) as parents/ guardians become incapacitated by or die from HIV/AIDS, distressed and discontinued businesses as people become too poor to patronize such ventures, and simply the high number of HIV-infected persons (Langmagne, 2016; Lund \& Agyei-Mensah, 2008).

Moreover, previous research has documented poorer housing in LMKM, with negative implications for the inhabitants' health, particularly PLWHAs. The Housing and Health Framework advanced by Dunn $(2002 ; 2004)$ drew a correlation between substandard housing and poor health. Dunn's framework is critically applicable to the study of PLWHAs. A compelling link has been established between inadequate housing and health, particularly for populations such as HIV-positive persons due to their compromised immunity system (Milloy, Marshall, Montaner, \& Wood, 2012; TeyeKau et al., 2018). While poor housing can ordinarily be generalized to Ghana (GSS, 2013a; Boamah, 2014), both anecdotal (National Catholic Health Services, 2010) and more substantive (GSS, 2013b) evidence indicate that the housing situation in LMKM may become worse with documented notably poor outcomes for the health of PLWHAs in LMKM (Tenkorang et al., 2017; Teye-Kau et al., 2018). This poses additional public health threats to PLWHAs in LMKM. Thus, LMKM is at an important intersection of two critical public health vulnerabilities. First, it has been buffeted by the bewildering effects of the HIV/AIDS pandemic (Langmagne, 2016; Lund \& Agyei-Mensah, 2008). Second, the hypothesis on housing and health underscores a higher toll on the health of PLWHAs living in LMKM (Tenkorang et al., 2017a; Teye-Kau et al., 2018).

A paucity of qualitative studies exists on the experiences PLWHAs live with in Ghana (Teye-Kau et al., 2018). Additionally, despite the numerous studies on HIV/ AIDS in Ghana, a paucity of scholarship exists on studies juxtaposing the several different aspects of contextual issues to better unearth the multiplicity of factors exposing PLWHAs to being vulnerable. This paper attempts to fill the gap in scholarship 
in the contexts of living with HIV/AIDS in Ghana in particular and sub-Saharan Africa in general. Unlike previous research on HIV/AIDS in Ghana, this paper uniquely gives prominence to the synergies between the catchment area's vulnerabilities for LMKM and for Ghana in general, and the intrapersonal vulnerabilities PLWHAs experience in their daily livelihoods (Collins \& Rau, 2001; Langmagne, 2016). Through the literature review and field data, this paper uniquely combines the aspects of communityrelated meso contexts with the PLWHAs-related micro contexts to shed light on some of the day-to-day vulnerabilities of PLWHAs. Thereby, it provides suitable entry points for supportive policies for PLWHAs (Department for International Development, 1999). Previous authors have underscored the importance of studying certain ill-health conditions in Africa and Ghana by understanding the synergies between the peculiarities in the sick individual's everyday life and the meso and macro structural settings (Aikins, 2015; Patel \& Stein, 2015). Specifically, the forms of deprivation, trauma, and social disadvantage have a strong correlation with poor health in Ghana and sub-Saharan Africa (Aikins, 2015; Patel \& Stein, 2015). They point more forcefully to the damaging effect marginalization, disadvantage, and inequality have on poor health in African settings (Aikins, 2015; Patel \& Stein, 2015).

The paper focuses on the on social contexts of HIV/AIDS in LMKM specifically and Ghana generally. It stresses the intersectionality between the study community's known vulnerabilities and the participants' individual situations to highlight their contextual susceptibility and pursues three specific objectives. First, the study explores some of the contextual circumstances PLWHAs face in their daily lives. Second, it highlights some of the challenging situations facing PLWHAs in Ghana's district with the greatest HIV-positive endemic. Third, it contributes to the literature regarding the nuances of living with HIV/AIDS in Ghana and sub-Saharan Africa. Previous studies have illuminated aspects of the effects of socio-cultural and community vulnerabilities and applied them to HIV/AIDS in LMKM (Fobil \& Soyiri, 2006; Langmagne, 2016; Lund \& Agyei-Mensah, 2008; Tenkorang et al., 2017a; Teye-Kau et al., 2018). All these studies on HIV/AIDS in LMKM have commented on the effect of several socio-cultural, economic, travel, ecological, and community organizations as precursors and outcomes of the scourge of HIV/AIDS in LMKM. All these previous researchers link poverty and vulnerability in LMKM to the plausible causation, experiences, and outcome of HIV/AIDS in LMKM as noted above. These are all examples of the dynamic individual-cum-interpersonal, multidimensional, historic, cultural, multi-directional, and co-constitutive interlinkages among PLWHAs in LMKM's experience with the disease, as well as other influences from meso and macro structures. For instance, Lund and Agyei-Mensah (2008) documented the community arrangements for taking care of HIV/AIDSrelated OVCs in the study district. 
This paper additionally contributes directly applying social context theory to PLWHAs in the study district, Ghana, and Sub-Saharan Africa generally as no previous study has focused on applying this theoretical framework. Social context theory provides an apt theoretical framework for discussing issues pertaining to the social framework. The subsequent sections in the paper include literature review on the peculiarities of HIV/AIDS in the study district, the theoretical framework being used, and methodology. These are followed by sections on the findings, discussion, and conclusions and recommendations.

\section{The Peculiar Socio-Cultural Context of HIV/AIDS in Lower Manya Krobo Municipality}

Previous researchers have attempted to explain Agormanya's high rates of HIV through diverse explanations, such as the Ghana government's failed resettlement program for people within the environs of Agormanya. Resettlement had displaced roughly 80,000 residents of the Agormanya catchment area after the Kpong and Akosombo dams were constructed (Girmay, 2006; Teye-Kau et al., 2018). Economic hardships resulted from the dams' destruction of arable lands and habitats. This led to a poverty-induced vulnerability toward HIV/AIDS (Sauvé et al., 2002; Teye-Kau et al., 2018). The effects the HIV/AIDS scourge itself had on the vulnerability of the LMKM catchment area directly and indirectly are another contextual issue worth highlighting. Previous authors have noted high death rates from HIV/AIDS, and marital failure and dissolution (Lund \& Agyei-Mensah, 2008; Langmagne, 2016). These have led to more vulnerabilities, such as higher burdens from HIV-orphaned children and widows, unsupervised youths and school drop-out/truancy, business failures due to poor patronage, unemployment due to stigmatization, poverty, and famine (Lund and Agyei-Mensah, 2008; Langmagne, 2016; Owusu \& Laar, 2018).

High levels of prostitution and non-regular condom use among LMKM's residents, early loss of virginity, and sex with multiple partners have also been blamed for the area's high HIV/AIDS rates (Asante, Fenny, \& Ahiadeke, 2007; Cassels, Jenness, Biney, Ampofo, \& Dodoo, 2014, Teye-Kau et al., 2018). The economic and political crises Ghana underwent in the late 1970s and early 1980s saw a mass exodus of both skilled and unskilled Ghanaians to neighboring countries, particularly Cote D'Ivoire and Nigeria, which have higher HIV infection rates than Ghana (UNAIDS, 2017). Facing limited options, many of the low-skilled female migrants, key among them Krobo women, resorted to prostitution (Fobil \& Soyiri, 2006; Teye-Kau et al., 2018). Those who returned after forceful repatriation in the early 1980s became key vectors in the transmission of the virus. 


\section{Theoretical Framework: Social Context Theory}

The importance social context has in better understanding health behavior and health-related issues has come to the fore in public health research (e.g., Parry, Thompson, \& Fowkes, 2002; Revenson \& Pranikoff, 2005; and Sorensen et al., 2003 as cited in Burke, Joseph, Pasick, \& Barker, 2009, p. 1). Elucidating social context is critical for better appraising and predicting health-related behaviors and decisions. In this regard, Burke et al. (2009, pp. 1, 3, 11) attempted a theoretical approach to social context emphasizing the interrelations of the different dimensions of social context and human health behavior. Burke et al.'s approach to social context proposes an improvement upon the Social Cognitive Theories (SCT) and Social Ecological (SE) models. Albert Bandura's social context theory is a leading theory on health behavior change. It examines the influence of context on individual health behavior by assessing the combined effect of the factor triad of personal/individual, environmental, and social on health behavior. These effects are considered to be reciprocal, dynamic, and interactive (Bandura, 1986, 1997, 2002; Redding, Rossi, \& Velicer, 2000; and Glanz, Lewis, \& Rimer, 2002 as cited in Burke et al., 2009, pp. 4-5). SE models are underpinned by the term ecology, which is "the study of the relationships between organisms and their environments" (Burke et al., 2009, p. 5). Similar to SCT, SE models combine several levels of influence on human behavior (i.e., intrapersonal, interpersonal, institutional, communal, and public policy processes) to explain human health behavior. SE models highlight the interdependence of specific environmental conditions and settings, as well as the interconnections between multiple settings and livelihood domains (Stokols, 1996, p. 286, as cited in Burke et al., 2009, p. 5).

Although these have hitherto championed multidimensional socially contextual explanations of health behaviors and related decisions, SCT and SE theories have some limitations. They relegate social contexts to the background and treat them as unidirectional and unchanging. Burke et al.'s (2009) social context theory proposed an improvement by positioning the forces of the social context on the individual as multi-directional and dynamic external influences on inter- and intra-personal factors. Informed by Pasick and Burke (2008), Burke et al. (2009, p. 2) defined social context pertaining to health as "the sociocultural forces that shape peoples' day-to-day experiences and that directly and indirectly affect health and behavior." These realms transcend individuals, their families, communities, organizations, and histories (p. 11). Usually situated within qualitative studies (e.g., see Pasick \& Burke, 2008; Burke et al., 2009; and Joseph, Burke, Tuason, Barker, \& Pasick, 2009; as cited in Burke et al. pp. 10-11), Burke et al.'s (2009) social context theory emphasizes the following:

1. "The relationship between the individual and one's social context is constantly dynamic, shaped, and constituted by social, cultural, economic, political, legal, historical, and structural forces." It is complex. 
2. It is "multi-directional and co-constitutive" and constantly information. The attribute of being co-constitutive implies that "they are formed in relation to and by each other and often influence people in ways of which they are not consciously aware" (p. 2).

3. It is multi-layered and encompasses the dual domains of cultural and social influence.

4. It often involves processes and elements of sub-conscious awareness (p. 2, 6).

Burke et al. (2009) noted that the myriad of social processes and forces that shape social context include institutions and organizations (such as clinics, schools, and community) as well as individual personal paths (e.g., family, interpersonal relationships). For emphasis, “...we view behaviour in relationship to the surrounding expectations, social structures, and resources rather than viewing behaviour as solely under individual control. We posit that these behaviours simultaneously constitute, and are constituted by the rules, relationships, expectations, and resources of social structures. Therefore, analyses of behaviour require theory that addresses the multiple interacting dimensions of social structures and people's awareness of, conformity with, and resistance to those structures" (p. 7).

Choosing Burke et al.'s (2009) social context framework has been informed by the objectives of the study and several themes derived from the data. These involve the documented vulnerability of our PLWHA participants and include their individual trajectories and experiences, as well as their family and other social backgrounds (Burke et al., 2009). Additionally, it includes LMKM residents' general poverty and vulnerability, as well as LMKM's documented poor socio-economic context in general as a geo-political study catchment area. In particular, it includes the unenviable impact of HIV/AIDS on LMKM as described by previous researchers (e.g., Lund \& AgyeiMensah, 2008; Langmagne, 2016). Thus, this study takes cognizance of both the antecedents and precedents of the holistic nature of the participants' personal and social experiences.

\section{Methods}

\section{Profile of the Study Area}

When collecting the data, our study area (LMKM) was one of 26 district/municipal administrative zones in the Eastern Region of Ghana. As of Ghana's last census in 2010, LMKM had 89,246 inhabitants and a land mass of $304.4 \mathrm{~km}^{2}$, which constitutes $12.4 \%$ of the Eastern Region (GSS, 2014; Owusu \& Laar, 2018). Its inhabitants are mostly farmers and fishermen of the Dangme ethnic group who speak Krobo. They 
inherit property from their father's lineage (Sedziafa, Tenkorang, \& Owusu, 2016). Due to the history of HIV/AIDS in the study area, the Government Hospital in Atua, near Agormanya, and the St. Martins de Porres Hospital in Agormanya have both been equipped as specialized HIV/AIDS-related care hospitals with specialized staff for catering to HIV-positive cases in the district and nearby vicinities (Tenkorang et al., 2017a; Tenkorang, Owusu, Laar, \& Yeboah, 2017b; Teye-Kau et al., 2018).

\section{Sampling}

The paper is linked to a larger research project studying the housing and health nexus for PLWHAs in LMKM. The paper has used information from the qualitative data to fill the context-specific gaps and peculiar meanings the project's quantitative data are unable to provide, as noted by Babbie (2013). The initial sampling process for the project was combined for both the survey and qualitative interviews. This paper is based on the qualitative component of the larger study that utilized in-depth interviews. The project studied the housing and health nexus for PLWHAs. The paper uses combined purposive convenience sampling (Guarte \& Barrios, 2006; Suri, 2011) and random sampling to select 38 participants who would routinely report to the Voluntary Counselling and Testing (VCT) centers of the Atua Government and the St. Martins de Porres hospitals for healthcare regarding HIV-related co-morbidities within the study period. A third healthcare facility was found in the study municipality when data was being collected. However, the two hospitals had been purposively selected due to the special attention that had been given to these study hospitals.

Based on two prior reconnaissance visits, we targeted 40 HIV-positive persons at each hospital per day for either qualitative interviews or surveys. The Principal Investigators (PIs) then prepared daily lists of all the attendees, of whom we randomly selected one third. Selecting a third of the attendees per day facilitated spreading our data collection over the study period, which strengthened our data by allowing the chance for as many different participants as possible to be selected over the designated study period. On a daily basis, each listed attendee to the hospital was given a number starting with one. These numbers were put on small pieces of paper, folded, and put in a pool. The daily selection process was completed by randomly picking each number, followed by tossing the remainder around vigorously and repeating the process till a third of the attendees had been selected.

Participants who made the list were given unique identification numbers to prevent respondents from being selected multiple times. When we had less than 40 hospital attendees in a day, we selected half of the available ones. On days when we our initial sample was less than $25 \%$ male, we purposively gave males a higher probability of inclusion in the sample by adding every fourth male from the list of males who had not made the initial sample. This was to compensate for the disproportionately lower 
number of male PLWHAs compared to females in the study district, Ghana, and SubSaharan Africa in general. For instance, females comprised more than $70 \%$ of the 618 new clients who visited orthodox healthcare facilities for HIV/AIDS clinical care in LMKM between January and June 2010 (Antwi, 2010; Owusu \& Laar, 2018). In 2018 in Ghana, $65 \%$ of those living with HIV/AIDS are women and $35 \%$ are men (GAC, 2019); at least 56\% of PLWHAs in Sub-Saharan Africa are female (UNAIDS, 2018). Participants gave verbal self-confirmation of their HIV-positive status. They were sampled on weekdays only to correspond with VCT workdays. The sampling was done separately for each hospital, with separate lists being prepared for those who reported to the VCTs.

We used one qualitative interviewer per hospital, whoever selected participants to interview took turns performing the qualitative or quantitative interview with a random initial start. The target was to have 15 qualitative interviews from each study site, as guided by previous authors who had posited that a key requirement in qualitative studies is to reach a thematic saturation of data (Guest, Bunce, \& Johnson, 2006; Baxter \& Eyles, 1997). This is provided well with 30 participants (Mason, 2010). Our final sample included 17 from St. Martins de Porres Hospital and 21 from Atua Government Hospital. We attained thematic saturation within the one month period designated for data collection, yielding 38 qualitative respondents. Generally, thematic saturation is reached when the themes from participants start to recur or become repetitive (Baxter \& Eyles, 1997; Sedziafa et al, 2016).

\section{Data Collection and Ethical Clearance}

We employed a qualitative analytical approach for this study. The data were collected in June-July, 2015. The qualitative data collection used an in-depth interview guide that had been pretested using four participants from both hospitals. The guide was finalized by introducing additional probing questions based on feedback from the pretesting. Based on the initial objectives of the project from which this paper emanates, some of the issues discussed are as follows: 1) housing arrangements/type and conditions, 2) housing and health, and 3) experience(s) with discrimination/stigma and/or abuse. Other issues are 4) current support needs, if any, who supports them, and whether the support they receive is adequate or not and 5) current healthcare seeking for HIV-related healthcare and the difficulties doing this. The rest include 6) health status (physical and mental [anxiety, depression, isolation, sadness, etc.]) and any health problems, and 7) demographic information.

We followed a rigorous system of ethical review involving multiple layers of assessment. We sought written clearance from Memorial University's Ethical Review Board at St. Johns, Newfoundland, Canada, and the Ethical Committee for Humanities at the University of Ghana, Legon. We also sought written clearance from Ghana 
Health Services' Ethical Review Board, as required for all studies occurring at its facilities. Furthermore, we obtained permission from the Eastern Regional Directorate of the Ghana Health Services, the LMKM Health Management Directorate, and the Directorates of the study hospitals.

To enhance data quality, interviewers completed a 3-day training course. The two Principal Investigators (PIs) for the project, which includes the author, supervised the data collection in addition to having designated field supervisors. All participants participated in an informed consent process. Written (or verbal if unable to write) consent was obtained prior to participation. Interviews took about 35-50 minutes per respondent. Based on participants' choices, the interviews were mostly conducted in Krobo, the indigenous language in the study localities. The same processes were undertaken at both study sites (Tenkorang et al., 2017a, 2017b).

\section{Data Analysis}

The data were transcribed verbatim by three of the research assistants who are indigenous to the study area and reviewed for accuracy. The author read through all the transcriptions and edited them to reflect participants' words verbatim before being finalized. Thematic content analysis has been applied, which allows a qualitative researcher to develop an overall synergy from key issues featured from each narrative (Lieblich et al., 1998). For this paper, coding was done independently by two research assistants using the professional software program NVivo (Version 11, QSR International, 2015). The coding was done using cross-case, case-oriented analysis. This means multiple cases were closely examined in detail. This led to the discovery of patterns, structures (types and relationships between the series of individual cases), causes, and consequences (Babbie, 2013, pp. 390-391).

Inter-coder agreement was reached following discussions among the coders, author, and a multilingual assistant, all of whom interrogated the meanings of the narratives' issues and contexts. Subsequently, the emerged themes were developed separately by the two coding assistants as one team and the author as the other. Further series of discussions after this process led to finalizing the themes for this paper. Due to the depth of information, our thematic analysis for this paper focuses on two issues: family life and responsibilities, and health status, healthcare seeking, and healthcare. Additional themes are covered in another paper (Owus \& Laar, 2018). Lastly, the grounded theory approach, based on constant comparison of cases within the earmarked themes (Babbie, 2013, pp. 392-393), has led to inductively using the social context theoretical approach. The summarized findings are supported with brief illustrative quotes (Burke et al., 2009), which are identified using the respondent's assigned number (see Table 1). 


\section{Results}

\section{Participants' Socio-Demographic Characteristics}

Our participants are comprised of six males and 32 females. The average age is 47.64 years (ranging from $25-68$ years). ${ }^{1}$ The vast majority have low socio-economic statuses. Most participants had less than a basic school education; six had no formal education. The majority $(n=24)$ of participants are indigenous Krobos. They all professed heterosexual orientation. Most are unemployed; working individuals are typically self-employed in the informal economy (see Table 1).

1 One respondent could not specify her age. 


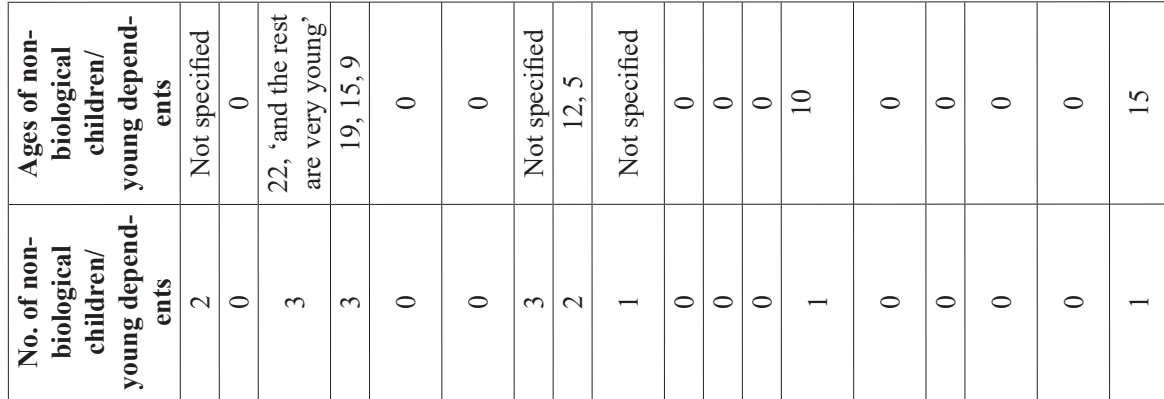

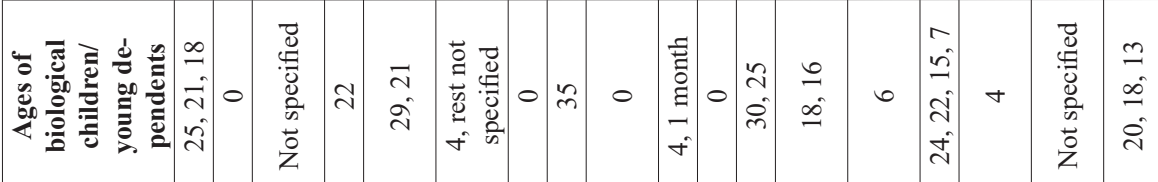

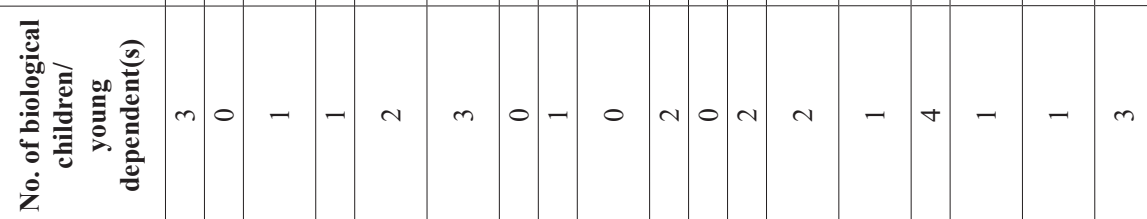

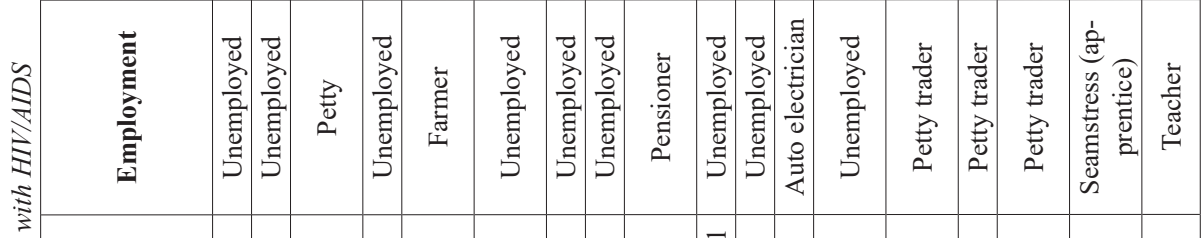

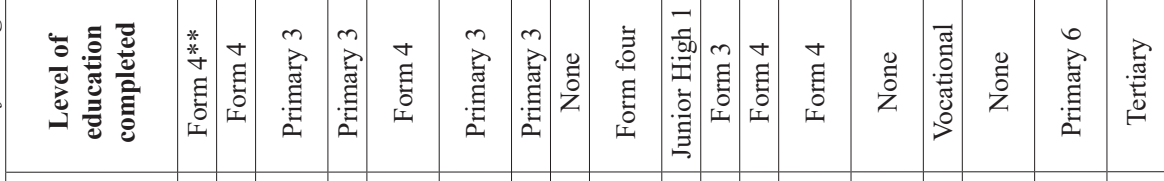

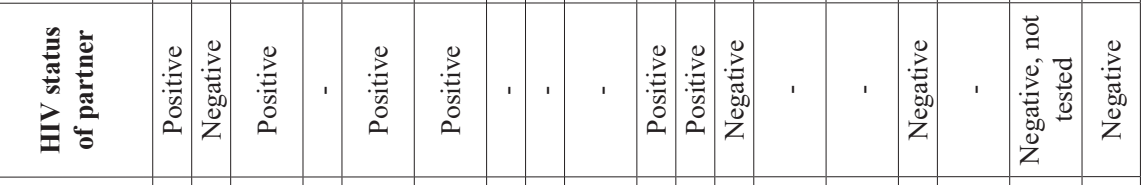

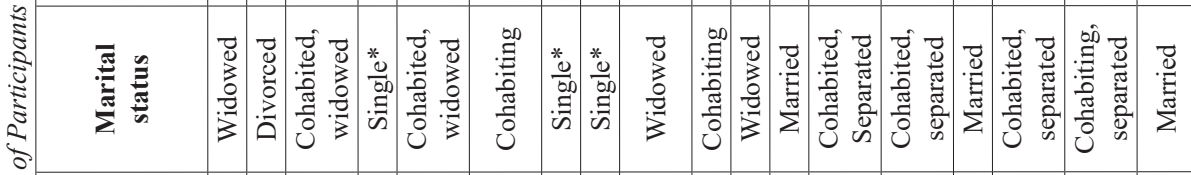
.

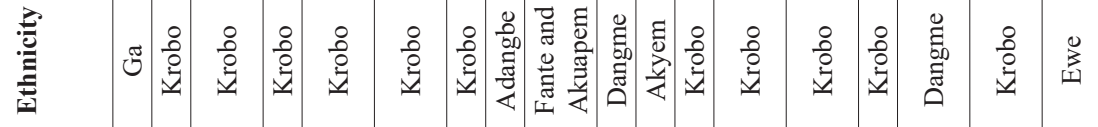

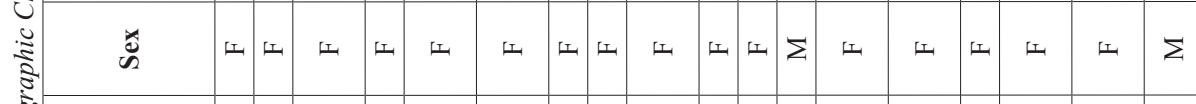

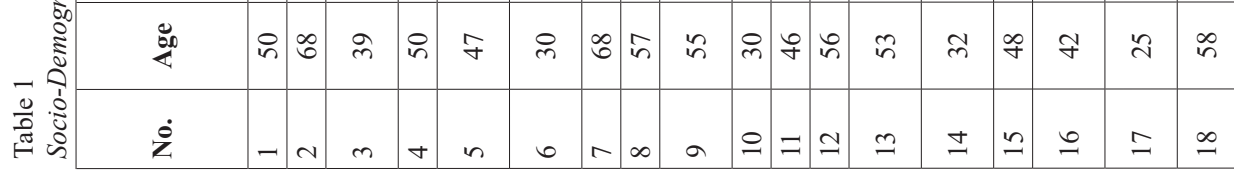




\begin{tabular}{|c|c|c|c|c|c|c|c|c|c|c|c|c|c|c|c|c|c|c|c|}
\hline 0 & $\begin{array}{l}n \\
0 \\
n \\
\stackrel{0}{n} \\
0\end{array}$ & 0 & $a$ & 0 & 0 & 0 & in & 0 & \pm & 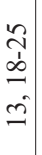 & $\hat{0}$ & $\begin{array}{l}n \\
\infty \\
\infty \\
0 \\
0\end{array}$ & 0 & $\begin{array}{l}0 \\
\stackrel{0}{0} \\
\stackrel{i}{1}\end{array}$ & 0 & 0 & 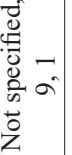 & $\begin{array}{c}n \\
n \\
0\end{array}$ & $\stackrel{n}{n}$ \\
\hline 0 & $\nabla$ & 0 & - & 0 & 0 & 0 & - & 0 & - & in & $N$ & $\nabla$ & 0 & $m$ & 0 & 0 & $m$ & $m$ & $N$ \\
\hline 0 & 0 & 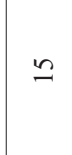 & $\stackrel{\circ}{\circ}$ & 0 & $\begin{array}{l}n \\
6 \\
\infty\end{array}$ & $\Rightarrow$ & $\begin{array}{l}\overrightarrow{\vec{\lambda}} \\
\overrightarrow{\hat{\lambda}}\end{array}$ & 0 & $\begin{array}{l}2 \\
\text { in }\end{array}$ & 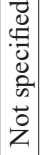 & $\circ$ & 0 & 0 & 0 & 0 & 0 & 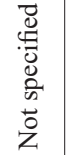 & $\begin{array}{l}\simeq \\
\simeq \\
\simeq\end{array}$ & 0 \\
\hline 0 & 0 & - & - & 0 & $m$ & $\sim$ & $N$ & 0 & $N$ & $\infty$ & - & 0 & 0 & 0 & 0 & 0 & $\infty$ & $N$ & 0 \\
\hline 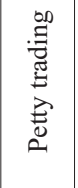 & 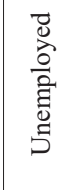 & 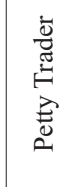 & 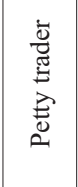 & 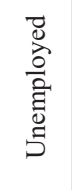 & 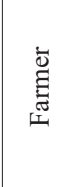 & 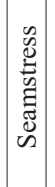 & 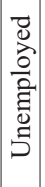 & 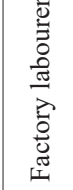 & 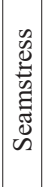 & 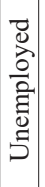 & 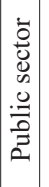 & 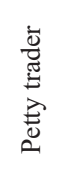 & 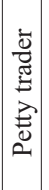 & 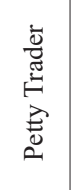 & 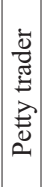 & 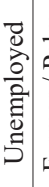 & 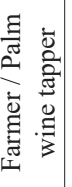 & 离 & 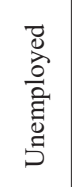 \\
\hline 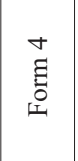 & 苛 & 离 & $\begin{array}{l}\tilde{\Xi} \\
\text { ż }\end{array}$ & $\begin{array}{l}N \\
\text { E్ } \\
\text { DI }\end{array}$ & 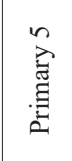 & 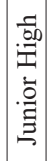 & $\begin{array}{c}- \\
\bar{\Xi} \\
0 \\
1 \\
1\end{array}$ & $\begin{array}{l}+ \\
\text { 囯 } \\
\text { I. }\end{array}$ & 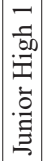 & 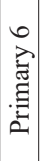 & 胥 & है & 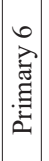 & 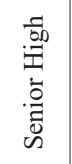 & 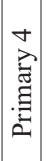 & $\begin{array}{l}\tilde{z} \\
\tilde{z} \\
z\end{array}$ & 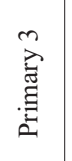 & 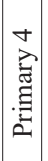 & $\begin{array}{l}0 \\
\text { त्ञ } \\
\text { 离 } \\
0\end{array}$ \\
\hline & & & & & 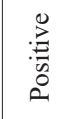 & 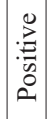 & $\ddot{\theta}$ & ' & 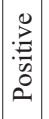 & ' & 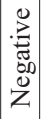 & ' & ' & 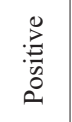 & 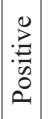 & 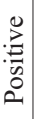 & $\begin{array}{l}\stackrel{0}{\vec{v}} \\
0 \\
0\end{array}$ & 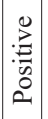 & \\
\hline 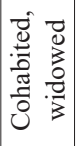 & 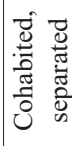 & 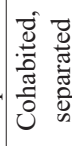 & 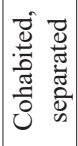 & 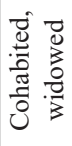 & 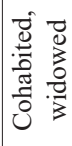 & 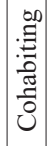 & 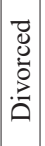 & 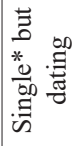 & 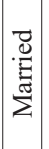 & 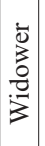 & 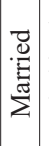 & 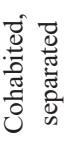 & $\begin{array}{l}* \\
\stackrel{0}{b 0} \\
\stackrel{\Xi}{\omega}\end{array}$ & 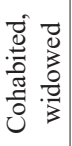 & $\mid \begin{array}{l}0 \\
0 \\
0 \\
0 \\
0 \\
0 \\
3 \\
3\end{array}$ & 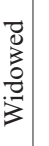 & $\begin{array}{l}\frac{\vec{J}}{\vec{E}} \\
\frac{\mathrm{J}}{\Sigma}\end{array}$ & 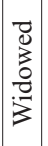 & 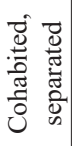 \\
\hline 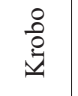 & 童 & 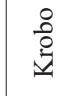 & 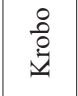 & 童 & $\begin{array}{l}8 \\
\text { : } \\
\text { ¿ }\end{array}$ & $\frac{\pi}{\mathrm{J}}$ & 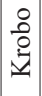 & $\frac{\text { 氶 }}{4}$ & 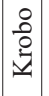 & . & $\begin{array}{l}0 \\
0 \\
0 \\
\vdots \\
2\end{array}$ & $\begin{array}{l}\circ \\
\text { 일 }\end{array}$ & 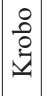 & 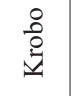 & $\mid \begin{array}{l}\overline{0} \\
\tilde{\omega}\end{array}$ & 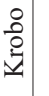 & 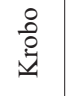 & $\pi$ & 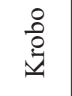 \\
\hline I & L & L & L & 工 & I & I & I & $\Sigma$ & 工 & $\frac{0}{\pi}$ & $\frac{0}{\pi}$ & I & II & II & 工 & 工 & $\Sigma$ & IL & 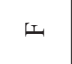 \\
\hline$\vec{q}$ & ก & Ұ & $\tilde{n}$ & กै & 이 & $\begin{array}{l}\infty \\
m\end{array}$ & 6 & $\stackrel{\infty}{+}$ & $\tilde{m}$ & $\stackrel{\infty}{+}$ & q & in & ర్ & in & $\vec{n}$ & in & $n$ & 光 & in \\
\hline 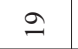 & ิㅗ & $\vec{\sim}$ & तี & $\tilde{\lambda}$ & $\stackrel{+}{\sim}$ & $\approx$ & $i$ & $\hat{\imath}$ & $\infty$ & ते & ஓ & $\bar{m}$ & ले & $m$ & $\ddot{m}$ & 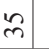 & r & $\hat{n}$ & $\underset{m}{\infty}$ \\
\hline
\end{tabular}




\section{Thematic Findings}

\section{The Context of Residential Arrangements, Family Relationships, and Family Responsibilities}

\section{Residential arrangements}

All but one participant lives in either a shared residential space or a multi-generational household. The sole respondent with a single-person residential arrangement said his brother also rented a room in the same house. Most participants are living in extended family homes and thus live in larger extended-family households, often with multiple siblings and multiple generations of descendants.

My father's is only one room. We are all in it. Oh, we are many. We are more than ten...one small room. Our fathers, the older generation, you know Krobos already. One of the rooms belonging to my father which was given to him ... when my brothers' wives come, that is where they go; when they themselves come, it's the same place; grandchildren, same... (R35)

I sell drinks but spend more than the profit we get from the work I am doing. I am taking care of some orphans in addition to my own children. (R22)

Another example is R29 (widower, too weak to work due to poor physical health):

Those [his biological children] who live with me are eight. [Interviewer: And how many grandchildren and other peoples' children live with you?] They are five. [Interviewer: But are you the one serving as their guardian?] Yes. Once in a while their parents will send us foodstuffs. The younger one is 13 years old-the one whose mother died at delivery - and the rest are between 18 and 25 [years].

Participants who rent accommodations and the few who own their places of abode often have smaller household sizes compared to the majority, who reside in extendedfamily homes. Nevertheless, extended family members are often part of their households.

\section{Other family members are HIV-positive}

Most (more than two-thirds) of the participants have an extended family member, usually a sibling or an aunt, who is/had been HIV-positive. The majority of the latter have died.

Yes and recently she was also diagnosed with the same virus. She was sick and, even though on medication, she was still weak. So I told one of our leaders, and he said I should bring her. So tomorrow I will come with her... it was just recently she was also diagnosed with the virus. (R22) 
In fact, one respondent mentioned that her aunt and three of the aunt's children were HIV-positive.

They were infected. Previously, when I was the only one with the disease, she wouldn't come even when I called, despite being my aunt. She raised me when my mother died...despite being diagnosed she refused to go for counseling. I came with her for counseling, and today she as well her three children are on medication because of that. [Interviewer: Why, her children were also infected?] They were infected. (R31)

Additionally, nine participants mentioned having lost their children, often babies, to HIV/AIDS. Two of them had lost two children each to HIV. [Interviewer: And you said you had two children but they both died?] "Yes." (R23). Six others said they have HIV-positive children; one has two of them.

The last of the children I had with my husband before his death; three years before his death, he was diagnosed positive afterwards. I come here for medication with him... One other person also has it. He was married when he contracted it... We are three who come to collect medication. All of us [are HIV-positive] apart from the older one. (R37)

\section{Participants are burdened with caring for other extended family members}

The prevalent extended family system in Ghana means that participants have to live with and/or mostly care for extended family members as well, particularly children. Only seven of the participants have no younger dependents (see Table 1). Of the rest, 19 have dependents who are not their biological children; mostly they are their grandchildren, younger siblings, or other extended family members. The non-biological child dependents had often been orphaned by AIDS, and a few are non-blood relations.

My biological children are 3 but I have 3 other children I am caring for, but one of them has been given to me [fosterage] so I add her to my biological children. But two of them are the children of my sibling who died, so they are under my care. They are many, my two siblings, my mother and six children. (R21)

My younger siblings who died left their children, and my sisters, whose positive statuses we didn't know early enough, also died of the disease leaving their children. But they--they don't stay with me... (R37)

\section{Participants have scant family support}

Participants have limited extended/nuclear family support. Several reasons accounted for this. First, the vast majority of them hides their HIV/AIDS status for fear of stigmatization, and therefore hides their need for assistance. Second, most of them said the family members who know about their HIV-positive status or are suspicious 
about it stigmatize them and do not help. Third, the vast majority (28 out of 38 ) of them are single (neither married nor co-habiting), widowed, or divorced. Fourth, 15 out of the 38 participants also mentioned having had at least one core family member die who had supported/would support them. These are often their parents or siblings.

Members of my extended family have no idea what has happened to me. My parents are all dead, and I don't trust my sisters and brothers, so I have not told them what is happening to me. (R1)

I don't have money, and because of my situation, I also cannot work...No one assists me, it was one of my elder brothers who was helping me but he died about six months ago. Ever since then things have not been easy for me at all. We don 't have any helper... so things have become difficult for my children and me. No other person is ready to help me... (R4)

... the condition I live in makes me think a lot, I ask if that will be the same situation if my mother were alive...so I was thinking if my mother were alive what would have happened, would she not have taken care of me? So I used to think a lot looking at what my father and siblings are doing to me, to the extent that I don't even get food to eat. (R23)

\section{Context of health status and healthcare seeking}

To bring greater clarity to the findings on this theme, the paper first describes the details of participants' HIV infection. As a group, the participants have been diagnosed HIV-positive for an average of 6.14 years (ranging from 6 months -13 years; median $=7$ years). Five participants were diagnosed over 10 years prior; equal numbers of participants $(n=15)$ were diagnosed 6-10 years or 1-5 years earlier. Three were diagnosed in 2014 , one year prior to the data collection.

\section{Nearly all participants only use allopathic medicine at the time of the interviews}

On the day of the interview, all but one respondent said they were at the hospital for routine healthcare and to re-stock their antiretroviral medications (ARVs). Also, all participants except one PLWHA receive only allopathic healthcare as of the time of interview, mostly in compliance with counseling from the clinics' staff. Close to $25 \%$ (8) of the participants said they initially had used herbal medicines and/or prayer camps (4) when they experienced comorbidities from HIV. The PLWHA who was still using a prayer camp at the time of interview explained that she needed divine protection in addition to receiving allopathic medicine: "As for prayer camps I go ... you know even though we have this virus, the devil is also disturbing us..." (R21). Two of them tried both the prayer camps and herbal medication. No particular socio-economic correlates have been found for these health-seeking behaviors. The participants who seek these types of alternative healthcare are not necessarily less educated or poorer. 
They explained that they did so at the initial stage of their sickness, mostly when they did not know the cause of their persistent ill-health.

Immediately it started; I didn't know what was happening to me. When I came and was told that searching for a cure would be futile, I stopped going. (R34)

I used to visit prayer camps and seek herbal medicines when I was ignorant about the illness, but I stopped going to those places when I became aware of it. (R16)

Two reported that the herbal medicine they had used was expensive, although one said it was good for her. "I went to an herbalist and he gave me some medicines so after taking those medicines I realized I was better (R4).

All but one had stopped using these alternative forms of treatment mostly because healthcare workers counseled them that HIV has no known cure. Thus, their best bet was to come to the clinic for antiretroviral therapy. They were also told that in reality the herbal and other treatments could worsen their condition.

At first I was going somewhere to buy medicine but they were very expensive...but I don't go there anymore. That place is not a hospital; it's like a clinic, herbal clinic. But we were told if we are taking herbal medicines we will get no better. (R25)

The remaining participants said they had never considered the option of alternative medicines because they were advised upfront by the clinical counselors to stick to orthodox medicine only.

We were told not to take herbal medicines, only those the doctor gives us. Yes, only the doctor, because we were told not to take traditional medicine. So although we often suffer from 'kooko' [Piles], I don't know how to treat it. I don't know. So I don't do that. (R37)

\section{Antiretroviral therapy (ART) improved their health}

The vast majority of them stated the antiretroviral therapy (ART: the set of treatment plans prescribed by their attending physician, including supportive care medications and antiretrovirals) to be very helpful to them, with an emphasis on the psycho-social counseling they receive from nurses at the HIV clinics. Thus, their health has generally improved.

It has been helpful to me, meaning, when I started doing the tests many died. Many died so I realize that it's been beneficial. I don't cough. When I had started, I used to cough. I coughed severely. But since I started on the medication I no longer experience that. (R36) 
In addition to the effects of ART, a few participants attributed health improvements to divine intervention (God).

The medicine is the reason I am alive. After God, it's the medicine. My health is good. By Jehovah God's grace I am in good health. I am in good health. (R31)

Improvement in their health somewhat ameliorated the stigma which their HIV-positive status had attracted to them. Some of those who said they experienced an improvement in their health status said that it relieved them of being suspected of having HIV.

Yes it [ART] has been very helpful to me. Ever since I started taking the medications I have never fallen sick. I have become like I used to be when I wasn't having the disease. Ever since I started taking the drugs I don't even have headaches. I am very strong so no one knows I have this disease. (R8)

I didn't grow lean; I had no rashes or anything, so nobody knew of it in the house. Before it was able to overcome me I rushed myself to the hospital. And by the grace of God when I came to the hospital they began giving me drugs so it was not able to overcome me for them to know I have HIV. (R21)

However, four participants stated their health to be deteriorating, while few experienced minimal improvement.

I'm not happy...See how all my legs hurt...My knees often feel weak and painful. They really hurt, Mama. Sometimes these hands feel numb, awh. So it doesn't make me happy. (R35)

Although the study did not establish a direct link between deteriorating health and adherence to ART, a few participants were aware that strict adherence to their ART would greatly improve their health: "I take the medication always that is why I am strong. " (R37).

\section{Reasons for poor health}

They often attributed suboptimal health to their difficulties taking the ARVs. The majority of participants, however, complained of general weakness and stated not being as strong as they had been prior to being diagnosed HIV-positive. A little over half mentioned other health challenges and co-morbidities, most commonly being easily-fatigued and getting malaria. Others include bodily pains, diarrhea, watery eyes, cough, catarrh, dizzy spells, chest pains, rheumatism, and rashes. Additionally, a few complained of degenerative diseases such as diabetes and high blood pleasure.

Because diabetes is even more dangerous than the HIV, formerly I was fatter than this and stronger, but the diabetes has now caused me to slim down. So diabetes is more dangerous than HIV; controlling it is more difficult than HIV. (R18) 
Kooko [piles] is what is causing the pain in my ear. For some time now Ifeel like there is some animal roaming in my ear but when I insert something too nothing comes out. (R16)

They attributed some of these to substandard housing, including poor environmental sanitation in/around their homes.

\section{Challenges to adhering to ART}

The participants also mentioned several impediments in their way that provoked missed appointments and non-compliance with prescribed healthcare. These included hunger and difficulty finding food and/or getting food on time for taking their medicines (mentioned by a majority).

The money, even what to eat, is a problem. If not for the fact that I go to church and our church members sometimes give me money I would have drank poison... When the day breaks I don't even have anything to eat. What prevents me from taking the drug is food. Food. Food...I was not getting food to eat so I became sick and the rate at which I was falling sick was high, I grew lean...Even though I was sick and in bed, so I would dress up and go beg for food. (R23)

Other challenges include poverty and the far distance from their homes to the clinics. They often lack money for transportation. They found the opportunity costs related to the long travel time/distance to the hospitals expensive, particularly taking time off from income-earning or childcare activities. They also linked some of these needs with the failure of society and family members to assist them.

...Some people are fortunate, they have benefactors. Some have helpers. Some have people who cook for them to eat. I have been hungry since morning. I haven t eaten. When I go [home] there'll be no food for me. These are my big problems. So when will I be healthy/strong? Currently I am only concerned about my health. (R34)

... because of poverty, I am not able to come to the hospital when my check-up date is due. Life in the village is not easy, and because the place is far from here, it becomes difficult. (R24)

\section{Inadequate supply of medicine}

Most participants also complain of a trend where, over the past couple of months they are being given a month's worth of medicine instead of the three month's rations they used to be given. This stemmed from inadequate supplies in the hospitals. Three of these respondents further mentioned not having adequate essential medicines due to their inability to pay for additional medicines out-of-pocket. Their national health insurance does not support those medicines: 
For some of us, the money to pay for our transportation to the hospital is a problem, so you can just imagine; how can we pay for the drug? This morning I have only three Ghan a cedis ${ }^{2}$ [\$0.75] on me and owe some money at the dispensary so I won't be given any drug that is not covered by the health insurance. The one that is not covered by the health insurance we have to pay five cedis [\$1.25] every month, so 15 cedis [\$3.75] for three months, so I will not be able to get the drugs today. (R4)

But currently where I am right now I need financial support because last March I was diagnosed with diabetes, so I've been collecting diabetes medicine together with the ARVs...Today they gave me only one set of HIV [medicines] like this, only one set, leaving two sets that I should come for another day. And then the diabetes injection, instead of five, I was given only one, then I have to go and buy four and that four, the last time I went to Juapong. It was 17 Ghana cedis [\$4.25]. It may be even more expensive this time; so 2.8million [old Ghana cedis every three months] [\$70.00] and even more... (R18)

\section{Hindrances from housing-related difficulties}

The majority who complained of difficulties in adhering to their ARV regimen referred to housing issues as a major hindrance; 10 participants $(26.34 \%)$ rent their accommodations, eight (21.10\%) own theirs. The highest proportion (19 [50\%]) share extended family accommodations, and one (2.63\%) was squatting (rent-free from nonfamily relations). A few of those who owned their accommodation still shared their space with extended family members, often in overcrowded conditions. Primarily, sharing accommodation is a hindrance because most participants are concealing their HIV-positive status from their house-mates and fear that disclosing their status will lead to them being ostracized. Participants who live in extended family accommodations and/or own their accommodations but share it in a restrictive space with extended family members are most likely to fear stigmatization, and thus need to hide their ARVs.

I live with my brother and his wife... I haven't told them, I only told one sister. I don't know whether they've noticed it, but I haven 't told them. [Interviewer: Or is there some fear that when you tell him, they will treat you with contempt?] I just can't tell him." [Interviewer: Any reason why? Are you scared they may no longer have a good relationship with you or they may ask you to leave, should you tell them about your illness?] "Yes, that's it... I keep it in hiding [Her ARVs]. (R16)

Additional hindrances to their healthcare seeking and performing a proper sick-role behavior include lack of formal education, which makes determining the right time to take their medication and/or go for their next hospital appointment difficult (mentioned by 4 out of 38). Other hindrances are missed work/income-earning opportunities

2 Four Ghana Cedis $=\$ 1$ US at the time of data collection. 
because of having to travel far to the clinic, as stated above, and the lack of alternative child-care assistance for their younger children.

I am staying at Ashiaman, so there are times I am not able to come on the set dates, I'm also uneducated and cannot read. The appointment cards, you have to be looking at it frequently in order to know your date, but at times when I am counting the days, I miscount, so sometimes I come a few days after my actual date. Besides that, I stay with my kids alone so I can only come when they are at school, so sometimes after dressing them up you realize it's late and are unable come. One is 10 years and the other is 9, but I have to dress them up for school. (R22)

Sometimes I don't have money or may not have time. Today I have had to run away from work because my boss, the one I am selling for, is not around so I have to hurry and go back. (R16)

\section{Side effects of ARVs}

Lastly, the vast majority of participants mentioned side effects from their ARVs as another hindrance to strict adherence to the ARVs. Six participants reported a current hindrance as the side effects from the ARVs.

I get scared even when I am about to open it. They said we should take only one. We experienced side effects when we started the medication. (R31)

The medicine is strong... I stopped, but the doctor warned me so I try to take it as often as I can. (R38)

Of these impediments to complying with their ARVs and clinic appointments, the one that seemed to affect their health most negatively was the lack of food for taking with their ARVs, followed by those who complained of side effects. Multi-collinear/ interacting effects also have been found among lacking food, not having money, lacking support from extended family members and romantic partners, and experiencing discrimination and stigmatization at home and from the general society (for instance, employers and rent owners). Participants who stated lacking food for ARVs, as well as those who reported discrimination and stigmatization in their homes, also reported poor health and multiple co-morbidities:

...I don't get food to eat... She got to know because it came to a time I was not getting food to eat, so I became sick and the rate at which I was falling sick was high. I grew lean. Even in that condition I will be in bed and will be hungry, but my father and sisters will cook and will turn their back on me and eat. They will not give me something to eat. I normally get diarrhea, and that prevents me from travelling because if we are on our journey and my stomach starts hurting what will I do?... I might have disgraced myself. What a shame (laughing). (R23) 
Sometimes the food won't be ready at five for getting your portion. Sometimes it so happens that you don't have money, so someone will have to give you food. This is what I am telling you. (R34)

Participants who miss clinic appointments would eventually make it up; those who hide their medication find ways around it to take it eventually, and those who miss the correct time for taking their medication often figure it out.

I haven't told anyone about it apart from my sister who went to the hospital with me. My daughter whom I stay in the same house with doesn't know I'm also HIVpositive. I hide my drugs in my bag. When I am going to work I take it along. In fact I take it everywhere I am going. (R8)

Hmmm. The issue is I don't know how to read, but I have to take 5 medications all on time. The times for this, that is the only thing, and they also know that I take my medication on time. I take the medicine out myself. If I ask the person whether it's five and they say yes, I would take my medicine. (R34)

\section{Discussion}

We applied Burke et al.'s (2009) social context model to our study. The framework brings the forces of social context to the fore in health behavior and healthcare seeking. It proposes a more complete and deeper understanding of health behavior and health disparities through the combined, reinforced interactive effect of personal, historical, social, legal, and structural organizations and arrangements for an improved understanding of health behaviors and related public-health issues. These are ordinarily complex and dynamic. Burke et al.'s (2009) framework posits a multi-dimensional and multi-directional influence of external socio-cultural (cultural, historical, community, national, including policies) on individual intra-personal factors to affect peoples' health behaviors and health.

Nearly all the participants mentioned having general body weaknesses. Furthermore, they mostly experienced several challenges to adhering to healthcare regimen they'd been prescribed. Foremost, most of the participants have food insecurities; 25 either do not get food to eat and/or don't get it on time for taking their ARVs. This affects their adherence to the prescribed regime for taking their medicines. This particularly has the consequence of retrogressing the respondents' health. Secondly, the vast majority of participants had or are currently experiencing side effects from their medicines. This has a similar effect of disrupting the participants' consistent adherence to their prescribed medications as they have to make the usual painstaking efforts to go for a change of medicine. Thirdly, substandard housing is a problem. As mentioned above, the literature posits suboptimal health for persons living in sub-standard housing, 
particularly for those with compromised health such as PLWHAs (Milloy et al., 2012; Tenkorang et al., 2017). The paper has also found them to have inadequate healthcare. For instance, some of them are unable to afford the ARVs and other medicines they need in a timely manner. Also, their NHIS coverage doesn't cater to some essential medicines, and they complained about expensive out-of-pocket payments. Overall, these factors affect their health negatively and interfere with healthcare seeking. While almost all in general stated that taking their ARVs to have improved their health, a few mentioned their health to be declining.

Guided by the social context framework, we proffer several explanations. Our findings first show the participants' current vulnerable livelihoods to have started with intra-personal and interpersonal issues. The participants' helplessness and poverty have a bearing on and perpetuate through their individual-level vulnerabilities, experiences, issues, and circumstances (Langmagne, 2016). At the individual level, they often lack adequate levels of financial, social, human, physical, and personal resources. Our findings support previous authors' findings and partly highlight the socio-economic factors that expose them to HIV and make taking more efficient care of their health impossible. For instance, being poor and unemployed and lacking supportive loving/social relationships for the most part have negative implications for their health. At least one respondent mentioned she had engaged in at-risk sex for purposes of finding food to eat. Langmagne (2016) observed that the burden of being HIV-positive is more manageable for richer people. Thus, inadequate control over these personal resources at the individual level also makes them less capable of managing their HIV/AIDS and taking better care of themselves. This is critical given their increased need for care induced by HIV/AIDS (Owusu \& Laar, 2018).

Regarding family factors, the participants clearly have very little social capital to aid them in their livelihoods. Quite alien to Ghanaian extended family norms, most of them do not have the support of key nuclear or extended family members. While this paper has not focused on PLWHAs' experiences of stigma and other treatments at the hands of others, several studies have attributed such near social isolation to the stigma, discrimination, and abuse PLWHAs experience in Ghana and Sub-Saharan Africa in general (Holzemer et al., 2007; NAP+ et al., 2014). Conversely, akin to the extended family system in Ghana, the PLWHA participants are more saddled beyond their own responsibilities. Most participants also have OVC dependents, mostly from relatives who had died of AIDS, due to the high rates of HIV in their communities. This further worsens their plight. It underscores the susceptibility of their societies, which in turn burdens them. It represents a doubleburden of social responsibilities beyond one's normal capability. Previous researchers (Lund \& Agyei-Mensah, 2008; Langmagne, 2016) have identified such burdens as part of what has perpetuated impoverishment in LMKM and contributed to the 
vulnerability of contracting HIV; OVCs may lack proper supervision and care, and other surviving family members may be burdened with taking care of such children in addition to their own biological children.

The intrapersonal and interpersonal vulnerability of our participants also has an inter-linkage within the context of their broader vulnerable community. We emphasize even more the community and cultural contexts that make our participants more vulnerable. Undeniably, the high scourge of the HIV/AIDS pandemic in LMKM has had reciprocal effects on our participants and left them more vulnerable. For instance, they are mostly single and/or widowed from HIV. This means that, especially for the female participants, they lack the support of a life partner to potentially help them with adult livelihood engagements, including caring for their younger dependents. This also increases their vulnerability.

The Ghanaian socio-economic and cultural contexts also influence our participants. Firstly, the transmission of HIV in Ghana was and still is shrouded in myth. This partly underpins the discrimination and neglect from the family members of those with HIV/ AIDS when their serostatus is known (Mill, 2003; NAP+ et al., 2014). GSS et al. (2009) explained further that such stigmatization and maltreatment of PLWHAs also thrives within a context of inadequate knowledge about the cause of HIV infection and its modes of transmission. In fact, only $27.2 \%$ of males and $19.9 \%$ of females aged 15-24 years in Ghana had comprehensive correct knowledge of HIV/AIDS in 2014 (GSS et al., 2015). In response to their coping with the stigma emanating from the HIV-positive status, Holzemer et al. (2007) noted across Sub-Saharan Africa that PLWHAs cope with their vulnerabilities by withdrawing socially.

Moreover, structural factors have an impact on PLWHAs. At the national level, Ghana's developmental history and frail economy have affected PLWHAs negatively. Contrary to what pertains to some Western countries (Boamah, 2014), adequately supporting vulnerable populations such as PLWHAs in Ghana is next to impossible. Nationally, the state lacks the ability to provide support with decent accommodations for the participants, as exists in some developed countries (Boamah, 2014: Tenkorang et al., 2017). The same applies to providing them with food rations. Availing funds for supplying adequate ARVs and/or absorbing catastrophic out-of-pocket payment for ARVs and other medicines essential for them is another case in point. Some of them lack essential medicines for controlling ailments such as diabetes and blood pressure. Poku et al. (2017) studied PLWHAs in Ghana's Greater Accra Region and similarly found ARVs to be under-stocked.

Furthermore, food insecurity has been flagged as a serious problem among PLWHAs in Ghana. Laar et al. (2015) studied 1,745 HIV-affected households as a nationally representation and found food insecurity to be prevalent among the participants. For 
instance, $61.3 \%$ had limited food portions, $59.5 \%$ ate fewer meals per day and/or totally skipped meals in a day, and $56.2 \%$ choose less expensive food items. Again, Laar studied 1,666 household affected by HIV/AIDS in four of the 10 regions in Ghana (Eastern, Brong Ahafo, Central, and Northern) in the second half of 2018. The study found $50 \%$ to be food insecure and 30\% to have borderline food insecurity. Food insecurity among the participants ranged from $24 \%$ (worst) in the Northern Region to $16.4 \%$ (least) in the Brong Ahafo Region. Low income mainly explained the food insecurity among the participants (Ghana News Agency, 2019).

The current plight of Ghana's National Health Insurance Scheme (NHIS) is another insufficiently fulfilled national effort at providing a safety net for the Ghanaian population (Institute of Statistical, Social, and Economic Research, 2019; Kodom, Owusu, \& Kodom, 2019). Our study found the NHIS to not adequately cover the vulnerable participants' health needs. Similarly, Ghana has been unable to achieve the proposed universal health coverage. Although Ghana provides additional safety-net support for the vulnerable populations in terms of the Livelihood Empowerment Against Poverty (LEAP), the gains are not widespread and has been insufficient at providing an appreciable safety net for our PLWHA participants. These issues point to the failure of certain national policies. The influence of social policy on intrapersonal health status and health behavior has been highlighted by previous authors emphasizing the social context (Stokols, 1996; Burke et al., 2009). Another important point in the case of this study is the historical influence of developments at Kpong and Akosombo on HIV/ AIDS in the LMKM catchment area (Girmay, 2006).

The study has some limitations. These include its lack of generalizability to persons other than our participants and the study district. Also, being cross-sectional, firmly determining cause-and-effect from this data is difficult. Additionally, recruiting the participants from VCT clinics may have biased the sample towards those with better social support and fewer barriers to accessing care. Furthermore, the bulk of the data made it necessary to focus on some aspects of the participants' livelihood experiences. Resultantly, other important factors such as their experiences of stigmatization have not been discussed in this paper to give a more holistic picture of their daily experiences. Finally, being a retrospective study, it may be subject to recall bias.

\section{Conclusion}

This paper has examined the effects of livelihood's social contexts on the health behaviors, health statuses, and related challenges over the livelihoods of 38 PLWHAs. The participants are from the municipality in Ghana's Eastern Region that has been impacted most by the HIV/AIDS pandemic. It focuses on aspects of their family situations/relations, health, and healthcare. The findings support our theoretical 
framework and show a co-constitutive/interactive effect among the participants' personal, interpersonal, community (social, cultural and economic), and national endowments over the livelihoods of the PLWHA participants.

The paper concludes these reciprocal, interdependent, multi-level, and multidirectional vulnerabilities and inadequate social protection opportunities at the family, community, and national levels in combination with the participants' intrapersonal and interpersonal deprivation to mostly incapacitate our PLWHA participants from optimally managing their HIV-positive status/livelihood. These have resulted in suboptimal health for them. As has been forcefully placed in the literature, these factors have irrefutable links with the international sex trade/travel and the onset of the HIV/ AIDS pandemic in Lower Manya Krobo Municipality and Ghana in general (Fobil \& Soyiri, 2006; Teye-Kau et al., 2018). In this study, we have found our PLWHAs to be very vulnerable. They exhibit precarious health statuses and generally deprived, subhuman livelihoods. The study thus affirms Burke et al.'s (2009) hypothesis of the need to interrogate the effect of the multi-faceted, multidimensional, and dynamic factors that impinge upon intrapersonal factors affecting health behavior and health status.

Designers of HIV prevention campaigns in Ghana in particular and Sub-Saharan Africa in general should strengthen campaigns against stigmatizing PLWHAs. Stakeholders should also continually educate and encourage families with PLWHAs to empathize with and be supportive of them. Furthermore, local, community, and national efforts at assisting in the care of vulnerable PLWHAs and OVCs should be strengthened. Similarly, stakeholders should encourage and support the education and apprenticeship/vocational training of youths in LMKM at more advanced levels to help reduce the perpetual individual- and community-level vulnerabilities that increase residents' exposure to HIV/AIDS. The current government's free senior high school education policy comes in handy in this regard. At the national level, greater efforts should be made to strengthen Ghana's economy against economic and health shocks.

\footnotetext{
Acknowledgements: This work was supported by the International Development Research Centre (IDRC), through the Canadian-African Research Grant; and the Department of Sociology, Memorial University of Newfoundland and Labrador. The contributions of Prof. Eric Y. Tenkorang towards sourcing funds for the original project that produced data for this paper is acknowledged.
}

Peer-review: Externally peer-reviewed.

Conflict of Interest: The author has no conflict of interest to declare.

Grand Support: The author declared that this study has received no financial support.

Hakem Değerlendirmesi: Dış bağımsız.

Çıkar Çatışması: Yazar çıkar çatışması bildirmemiştir.

Finansal Destek: Yazar bu çalışma için finansal destek almadığını beyan etmiştir. 


\section{References/Kaynakça}

Aikins, A. D. G. (2015). Mental illness and destitution in Ghana: A Social-psychological perspective. In E. Akyeampong, A. G. Hill, \& A. M. Kleinman (Eds.), The culture of mental illness and psychiatric practice in Africa (pp. 112-143). Bloomington: Indiana University Press. Retrieved June 26, 2019 from http://www.jstor.org/stable/j.ctt16gz69f.6

Antwi, I. K. (2010) 2010-half-year HIV/AIDS Review report of the Lower Manya Krobo District. Atua, Ghana: Ghana Health Services. Retrieved May 20, 2018 from http://www.ghanaids.gov. gh/gac1/aids_info.php

Asante, F. A., Fenny, A. P., \& Ahiadeke, C. (2007). National AIDS Spending Assessment 2005 and 2006 level and flow of resources and expenditure to confront HIV/AIDS. Accra: Ghana AIDS Commission, Institute of Statistical, Social and Economic Research, Joint United Nations Programme on HIV/AIDS. Retrieved from http://data.unaids.org/pub/report/2007/nasa ghana_0506_20070816_en.pdf

Babbie, E. R. (2013). The practice of social research (13th ed.). Belmont, CA: Wadsworth Cengage Learning.

Bandura A. (2002). Social cognitive theory in cultural context. Applied Psychology, 51(2), 269-290.

Bandura, A. (1986). Social foundations of thought and action: A social cognitive theory. Englewood, NJ: Prentice Hall.

Bandura, A. (1997). Self-efficacy: The exercise of control. New York: Freeman.

Baxter, J., \& Eyles, J. (1997). Evaluating qualitative research in social geography: Establishing 'rigor' in interview analysis. Transactions of the Institute of British Geographers, 22(4), 505-525.

Boamah, N. A. (2014). Housing policy in Ghana: The feasible paths. Ghana Journal of Development Studies, 11(1), 1-18.

Burke, N. J., Bird, J. A., Clark, M. A., Rakowski, W., Guerra, C., Barker, J. C., \& Pasick, R. J. (2009). Social and cultural meanings of self-efficacy. Health Education \& Behavior, $36(5 \mathrm{suppl}), 111 \mathrm{~S}-128 \mathrm{~S}$.

Burke, N. J., Joseph, G., Pasick, R. J., \& Barker, J. C. (2009). Theorizing social context: Rethinking behavioural theory. Health Education \& Behavior, 36(5_suppl), 55S-70S. https://dx.doi. org $/ 10.1177 / 1090198109335338$

Cassels, S., Jenness, S. M., Biney, A. A., Ampofo, W. K., \& Dodoo, F. N. A. (2014). Migration, sexual networks, and HIV in Agbogbloshie, Ghana. Demographic Research, 31, 861-888. https:// dx.doi.org/10.4054/DemRes.2014.31.28

Collins, J., \& Rau, B. (2000). AIDS in the context of development. Geneva: United Nations Research Institute for Social Development.

DfID, U. K. (1999). Sustainable livelihoods guidance sheets. London: DFID, 445. Retrieved June 13, 2015 from http://www.eldis.org/vfile/upload/1/document/0901/section2.pdf

Dunn, J. R. (2002). The population health approach to housing: A framework for research. Ottawa: Canada Mortgage and Housing Corporation.

Dunn, J. R. (2004). Housing and population health-research framework (Research Highlight, Socio-economic series 04-016). Canada Mortgage and Housing Corporation, Ottawa, Ontario: Canada. Retrieved May 20, 2018 from https://www.cmhc-schl.gc.ca/odpub/pdf/63463. pdf?fr $=1490528940366$

Fobil, J. N., \& Soyiri, I. N. (2006). An assessment of government policy response to HIV/AIDS in Ghana. Journal of Social Aspects of HIV/AIDS, 3(2), 457-465. 
Ghana AIDS Commission. (2015a) 2014 HIV Sentinel Survey Report. Ghana. Accra: Author.

Ghana AIDS Commission. (2015b). Country AIDS response progress report-Ghana. Retrieved from https://www.unaids.org

Ghana AIDS Commission. (2017) Volta, Brong Ahafo top HIV prevalence cases for 2016. [Online].

Ghana AIDS Commission. (2019). Summary of the 2018 sentinel survey report. Accra: Author

Girmay, Y. (2006). Assessing the environmental impacts of a hydropower project: The case of Akosombo/Kpong Dams in Ghana (Master's thesis). University of Stockholm, Sweden.

Glanz, K., Lewis, F. M., \& Rimer, B. K. (2002). Health behavior and health education: Theory, research and

GNA. (2019). Food insecurity among HIV-affected households threatens disease management. Accra: GNA. Retrieved November 19, 2019 from https://www.businessghana.com/site/news/ general/187014/Food-insecurity-among-HIV-affected-households-threatens-diseasemanagement

GSS, GHS and ICF Macro. (2015). 2014 Ghana Demographic and Health Survey. Accra: Authors

GSS, GHS, and ICF Macro. (2009). Ghana Demographic and Health Survey 2008. Accra, Ghana: Authors

GSS. (2013a). 2010 Population \& Housing Census. National analytical report. Accra: Author.

GSS. (2013b). 2010 Population \& Housing Census. Regional analytical report. Eastern Region. Accra: Author.

GSS. (2014). 2010 Population and Housing Report: District Analytical Report, Lower Manya Krobo Municipal. Retrieved July 14, 2018 from http://www.statsghana.gov.gh/docfiles/2010_District_ Report/Eastern/LOWER\%20MANYA\%20KROBO.pdf

Guarte, J. M., \& Barrios, E. B. (2006). Estimation under purposive sampling. Communications in Statistics-Simulation and Computation, 35(2), 277-284.

Guest, G., Bunce, A., \& Johnson, L. (2006). How many interviews are enough? An experiment with data saturation and variability. Field Methods, 18(1), 59-82.

Holzemer, W. L., Uys, L., Makoae, L., Stewart, A., Phetlhu, R., Dlamini, P. S., Greeff, M., ... Naidoo J. (2007). A conceptual model of HIV/AIDS stigma from five African countries', Journal of Advanced Nursing, 58(6), 541-551.

ISSER. (2019). Ghana Social Development Outlook 2016 (pp. 36-71). Accra: Author.

Joseph, G., Burke, N. J., Tuason, N., Barker, J. C., \& Pasick, R. J. (2009). Perceived susceptibility to illness and perceived benefits of preventive care: An exploration of behavioral theory constructs in a transcultural context. Health Education \& Behavior, 36(5_suppl), 71S-90S.

Kodom, M., Owusu, A. Y., \& Kodom, P. N. B. (2019). Quality healthcare service assessment under Ghana's national health insurance scheme. Journal of Asian and African Studies, 54(4), 1-19. https://dx.doi.org/10.1177/0021909619827331

Laar, A. K, Manu A, Laar M, El-Adas, A., Amenyah, R., Atuahene, K., Quarshie, D. Adjei, A. A., Quakyi, I. (2015). Coping Strategies of HIV-affected Households in Ghana. BMC Public Health, 15(1), 166.

Langmagne, S. (2016) High HIV/AIDS prevalence in a suburban area in Ghana: A context analysis of its relationship to human trafficking (Doctoral dissertation, University of Saskatchewan, Canada).

Lieblich, A., Tuval-Mashiach, R., \& Zilber, T. (1998) Narrative research: Reading, analysis, and interpretation (Vol. 47). Thousand Oaks, CA: Sage. 
Lund, R., \& Agyei-Mensah, S. (2008). Queens as mothers: The role of the traditional safety net of care and support for HIV/AIDS orphans and vulnerable children in Ghana. Journal of Geography, 71(2-3), 93-106. https://dx.doi.org/10.1007/s10708-008-9145-9

Mason, M. (August 2010). Sample size and saturation in $\mathrm{PhD}$ studies using qualitative interviews. In Forum qualitative Sozialforschung/Forum: Qualitative Social Research, 11(3).

Mill, J. E. (2003). Shrouded in secrecy: breaking the news of HIV infection in Ghanaian women. Journal of Transcultural Nursing, 14(1), 6-16.

Milloy, M. J., Marshall, B. D., Montaner, J., \& Wood, E. (2012). Housing status and the health of people living with HIV/AIDS. Current HIV/AIDS Reports, 9(4), 364-374. https://doi.org/10.1007/ s11904-012-0137-5. (Accessed: 24 June 2018).

NACP. (2003). Estimating national HIV prevalence in Ghana using sentinel surveillance d a t a . National AIDS/STI Control Programme, Disease Control Unit, Ministry of Health. Accra.

NACP. (2016) 2016 HIV Sentinel Survey Report, Ghana. Accra: Disease Control Unit, Ministry of Health.

NAP+, GAC, \& UNAIDS. (2014) Persons Living with HIV Stigma Index Study, Ghana. Revised Report. Accra, Ghana, NAP+, GAC and UNAIDS. Retrieved July 12, 2018 from http://www. stigmaindex.org/sites/default/files/reports/GHANA\%20Stigma\%20Index\%20report\%202014.pdf

National Catholic Health Services. (2010) St. Martin De Porres, Agomanya, E/R-2010 Annual Report. Agomanya: National Catholic Health Services. Retrieved March 10, 2018 from http:// stmartinshospital.org/reports/annual_reports/Annual\%20Report\%20-\%20\%202010.pdf

Owusu, A. Y., \& Laar, A. K. (2018). Managing HIV-positive serostatus in Ghana's Most HIV concentrated district: Self-perceived explanations and theoretical discourse. African Journal of AIDS Research, 17(1), 82-90. http://doi.org/10.2989/16085906.2017.1419268

Parry, O., Thomson, C., \& Fowkes, G. (2002). Cultural context, older age and smoking in Scotland: Qualitative interviews with older smokers with arterial disease. Health Promotion International, 17(4), 309-316.

Pasick, R. J., \& Burke, N. J. (2008). A critical review of theory in breast cancer screening promotion across cultures. Annual Review of Public Health, 29, 351-368.

Patel, V., \& Stein, D. J. (2015). Common mental disorders in sub-Saharan Africa: The triad of depression, anxiety and somatization. In E. Akyeampong, A. G. Hill, \& A. Kleinman (Eds.), The culture of mental illness and psychiatric practice in Africa (pp. 50-72). Bloomington, IN: Indiana University Press.

Poku, R. A., Owusu, A. Y., Mullen, P. D. Markham, C., \& McCurdy, S. A. (2017). HIV antiretroviral medication stock-outs in Ghana: Contributors and consequences. African Journal of AIDS Research, 16(3). https://www.ajol.info/index.php/ajar/article/view/162593

practice. San Francisco: Jossey-Bass.

QSR International. (2015). NVivo Professional Version 11. Boston: Author.

Redding, C, Rossi, J, Rossi, S. R, Velicer, W. F, \& Prochaska, J. O. (2000). Health behaviour models. The International Electronic Journal of Health Education, 3, 180-193.

Revenson, T. A., \& Pranikoff, J. R. (2005). A contextual approach to treatment decision making among breast cancer survivors. Health Psychology, 24(4), 93-98. 
Sauvé, N., Dzokoto, A., Opare, B., Kaitoo, E. E., Khonde, N., Mondor, M., ... Pepin, J. (2002). The price of development: HIV infection in semiurban community of Ghana. Journal of Acquired Immune Deficiency Syndrome, 20, 402-408. http://dx.doi.org/10.1097/00126334-200204010 00012

Sedziafa, A. P, Tenkorang, E. Y., \& Owusu, A. Y. (2016) “... he always slaps me on my ears:” The health consequences of intimate partner violence among a group of patrilineal women in Ghana. Culture, Health \& Sexuality, 18(12), 1379-1392. http://dx.doi.org/10.1080/13691058.2016.118 7291

Sorensen, G., Emmons, K., Hunt, M. K., Barbeau, E., Goldman, R., Peterson, K., ... Berkman, L. (2003). Model for incorporating social context in health behaviour interventions: Applications for cancer prevention for working-class, multiethnic populations. Preventive medicine, 37(3), 188-197.

Stockols, D. (1996). Translating social ecological theory into guidelines for health promotion. American Journal of Health Promotion, 10, 282-298.

Suri, H. (2011). Purposeful sampling in qualitative research synthesis. Qualitative Research Journal, 11 (2), 63-75. http://dx.doi.org/10.3316/QRJ1102063

Tenkorang, E. Y., Owusu, A. Y, \& Laar, A. (2017a). Housing and health outcomes of persons living with HIV/AIDS (PLWHAs) in the Lower Manya Krobo District, Ghana. Journal of Health Care for the Poor and Underserved, 28(1), 191-215. http://dx.doi.org/10.1353/hpu.2017.0017

Tenkorang, E. Y., Owusu, A. Y., Laar, A. K., \& Yeboah, E. H. (2017b). Housing, psychosocial and adherence counselling among HIV+ persons in Ghana. Health Promotion International. http:// dx.doi.org/10.1093/heapro/dax072

Teye-kau, M., Tenkorang, E. Y. \& Adjei, P. B. (2018). Revisiting the housing-health relationship for HIV-positive persons: Qualitative evidence from the Lower Manya Krobo District, Ghana. Qualitative Health Research, 28(8) 1217-1228. http://dx.doi.org/10.1177/1049732318764646

UNAIDS. (2017) Ghana. [Online]. Retrieved July 24, 2015 from http://www.unaids.org/en/ regionscountries/countries/ghana. unaids.org/sites/default/files/country/documents/GHA narrative_report_2015.pdf

UNAIDS. (2018). Women and Girls and HIV. Geneva, Switzerland: Author.

UNAIDS/GAC. (2014) Country AIDS Response Progress Report - Ghana Reporting Period January 2012 - December 2013. Retrieved July 24, 2015 from http://www.unaids.org/sites/default/files/ country/documents//file\%2C94605\%2Ces 